\title{
Feeding habits of children aged 6 to 12 months and associated maternal factors
}

\author{
Silvia Regina D. M. Saldiva, ${ }^{1}$ Maria Mercedes Escuder, ${ }^{2}$ Lenise Mondini, ${ }^{1}$ \\ Renata B. Levy, ${ }^{3}$ Sonia I. Venancio' ${ }^{1}$
}

\begin{abstract}
Objective: To identify the feeding practices of children aged 6 to 12 months of age and associated maternal factors.

Methods: This was a cross-sectional study analyzing data from the 2004 Breastfeeding and the Municipalities Project, which was implemented in 136 municipalities in the state of São Paulo, Brazil, with 24,448 children. The foods these children ate were profiled according to the number of children who had been given breastmilk and/or other foods during the previous 24 hours, and based on this data the probability of consumption of each food at each age was estimated by means of probit analysis.
\end{abstract}

Results: It was observed that $50 \%$ of the sample were being given breastmilk, $77 \%$ other types of milk, $63 \%$ porridge, $87 \%$ fruit, $78 \%$ soups, $64 \%$ the family meal, $58 \%$ meals including beans and $36 \%$ soup or meals containing meat. The probability of a 6 -month-old child being given soup is elevated $(78 \%)$, while for the family meal it is low $(39 \%)$, and the probability of being fed breastmilk is $59 \%$, lower than for other milks $(70 \%)$ and than for porridge (63\%). Associations were observed between milk-based meals and primiparous mothers, mothers employed outside the home and mothers who had spent longer in education. Similar findings were observed for soups, added to maternal age of more than 20 years. The family meal was associated with mothers under 20 years old, mothers who were not employed outside the home, mothers with fewer years' education and multiparous mothers.

Conclusions: Excessive consumption was observed of liquid and semi-solid foods, suggesting that appropriate guidance on complementary feeding is needed, taking into account age, primiparity, education and employed mothers.

J Pediatr (Rio J). 2007;83(1):53-8: Feeding habits, breastfeeding, weaning, infant nutrition.

1. Doutora. Núcleo de Nutrição e Saúde, Instituto de Saúde, Coordenadoria de Ciência, Tecnologia e Insumos Estratégicos de Saúde (CCTIES), Secretaria Estadual de Saúde (SES), São Paulo, SP, Brasil.

2. Mestre. Núcleo de Epidemiologia, Instituto de Saúde, CCTIES, SES, São Paulo, SP, Brasil.

3. Mestre. Núcleo de Nutrição e Saúde, Instituto de Saúde, CCTIES, SES, São Paulo, SP, Brasil.

Manuscript received Jun 08 2006, accepted for publication Oct 102006.

Financial support: Conselho Nacional de Desenvolvimento Científico e Tecnológico (CNPq), process no. 473.328/03-8.

Suggested citation: Saldiva SR, Escuder MM, Mondini L, Levy RB, Venancio SI. Feeding habits of children aged 6 to 12 months and associated maternal factors. J Pediatr (Rio J). 2007;83(1):53-8.

doi 10.2223/JPED.1588

\section{Introduction}

A child's first years of life are critical, being characterized by a high rate of growth and intense maturation, and nutrition has a fundamental role to play in assuring survival and adequate growth. The quality and quantity of foods eaten are extremely important for development and have lifelong repercussions. ${ }^{1,2}$

The World Health Organization (WHO) recommends exclusive breastfeeding for the first 6 months of life and continuation of breastfeeding until 2 years of age, together with the introduction of complementary foods. ${ }^{3}$ 
Breastmilk alone is capable of meeting all of children's' requirements up to until 6 months, but, after this period it must be complemented with adequate foods in order to supply nutritional requirements and prevent infant mortality and morbidity, including malnutrition and overweight. ${ }^{4}$

Any food other than breastmilk that is given to a breastfeeding child is defined as a complementary food. ${ }^{5}$

From a nutritional point of view, premature introduction of complementary foods can be disadvantageous because it reduces the duration of breastfeeding, interferes with absorption of important nutrients from breastmilk and it increases the risks of contamination and allergic reactions. On the other hand, late introduction of complementary foods is also disadvantageous because children's energy requirements will not be met, resulting in deceleration in growth and increased risk of malnutrition and micronutrients deficiencies. ${ }^{5}$

Infant feeding practices are influenced by the family environment, by information provided by health professionals and also by the media, through advertising by food manufacturers. ${ }^{4,6}$

Over recent years new concepts have emerged on infant feeding and recently the Brazilian Health Ministry launched a guide aimed at updating health professionals and consolidating their knowledge on infant feeding. ${ }^{5}$ There is, therefore, a real need to investigate the pattern of complementary food introduction and to identify maternal characteristics that could guide actions aimed at promoting healthy complementary feeding practices.

Since 1998 the São Paulo State Health Department, in the form of the Instituto de Saúde, has been running the Breastfeeding and the Municipalities Project (AMAMUNIC), the objective of which is to determine breastfeeding prevalence and to assess feeding practices during the first year of life based on the results of surveys carried out during national vaccination campaigns.

\section{Methods}

This was a cross-sectional study, analyzing data from the 2004 AMAMUNIC project, carried out in 136 municipalities (21\%) in the state of São Paulo, Brazil.

Municipalities participated by their own choice and the AMAMUNIC project was the responsibility of the municipal healthcare manager.

\section{Sample}

Where municipalities had populations of up to 4,000 children under the age of 1 year, the survey covered the whole population. In municipalities with larger infant populations, two-stage cluster sampling was used, according to procedures recommended by Silva. ${ }^{7}$ Assuming that children would not be distributed uniformly across the vaccination centers (the clusters), subgroups were drawn in two stages to achieve probability proportional to cluster size. During the fist stage, vaccination centers were chosen, and then children were chosen systematically from each cluster. The resulting sample is considered self-weighting.

For this study, when the individual municipal databases were combined to analyze all 2004 participants as a single set, data were weighted in inverse proportion to the sample fraction.

The study data covers 24,448 children aged 6 to 12 months who attended health centers during the vaccination campaign period.

\section{Data collection}

Two representatives from each Municipal Health Department were trained in order to standardize data collection procedures. These professionals were then responsible for training interviewers to carry out the survey, interviewing the person who had brought each child for vaccination.

The questionnaire employed was developed for a survey of Brazilian state capitals in 1997 and has been standardized since 1998 as the instrument used for surveys in the state of São Paulo. The instrument follows WHO recommendations for collecting indicators on infant feeding practices in population studies, utilizing data on the current status of infants' feeding by means of a 24 -hour dietary recall. ${ }^{3,8}$

Consumption was analyzed qualitatively of breastmilk, other milks, porridge (a pasty meal prepared with flour or other thickening agent), soup (savory, liquid or pasty meal), the family meal (solid savory meal that contains entire pieces of ingredients and which is similar to adult food), water, tea, fruit juice and fruit (in pieces or mashed). If soup and/or the family meal were mentioned, the instrument went on to ask whether these preparations contained beans and/or meat. The person responsible for children younger than 1 year was asked the questions on nutrition, but only when that person was the mother were the questions on her age, number of years in education, occupation and number of children posed.

\section{Data analysis}

Data were input on the Amamunic software application and sent to the Instituto de Saúde to be collated into a single database. When the consistency of data was verified, 397 children $(0.76 \%)$ were excluded because information on sex was missing, or because their age was incompatible with the study age group, leaving a total of 24,448 children. 
Feeding habits were analyzed in terms of the frequency of children fed breastmilk and each of the other categories of foods/preparations during the previous 24 hours. Additionally, we calculated the incidence of the WHO-proposed timely complementary feeding (TCF) indicator, which is a measure of the proportion of children aged 6 to 9 months who are still breastfeeding and also eating solid and/or semi solid foods. ${ }^{3}$

For the purposes of this study, we defined children as on TCF if they were aged 6 to 9 months and had fed on breastmilk and at least one savory meal (soups or the family meal).

The probability of consumption of each food group was estimated by means of probit analysis using weighted linear regression, taking the total sample of children studied. Using this method, results suffer less influence from month-to-month sampling fluctuations. ${ }^{9}$

The data displayed in graph form represent estimated probabilities for the consumption of foods at different ages and were produced using Excel for Windows.

In order to study associations between the consumption of foods/preparations and maternal characteristics, 20,366 children who had been brought by their mothers were analyzed (83.5\%). This analysis employed logistic regression, and measurements of association (odds ratios) were estimated for points and $95 \%$ confidence intervals. $\mathrm{Bi}$ and multivariate models were constructed for the event-response of the consumption of "milky meals" (other milks and/or porridge), "soups" and "family meals". The independent variables were classified dichotomously: age of mother ( $<20$ years/ $\geq 20$ years); occupation (employed outside of home/does not work outside of home); education ( $\leq 8$ years'/> 8 years' in education) and primiparous (yes/no).

Variables with $\mathrm{p}<0.20$ according to the Wald test were selected for the bivariate models. Variables with $p<0.05$, according to the same test, were selected for the final model (Hosmer et al. ). ${ }^{10}$

The software program SPSS version 6.0 was used for the probit analysis and logistic regression.

This study was approved by the Research Ethics Committee at the Instituto de Saúde in 2003, and all children participated after free and informed consent had been obtained from the mother or adult responsible.

\section{Results}

The distribution of children by sex was $50.3 \%$ males and $49.7 \%$ females. Distribution by age across the different municipalities was homogeneous, with a median of 10 months.
In relation to maternal characteristics, it was observed that $45.6 \%$ were primiparous, $14.1 \%$ were less than 20 years old, $67 \%$ were not employed outside the home and $48.2 \%$ had studied for 8 years or less.

Analysis of the foods consumed during the previous 24 hours by children aged 6 to 12 months revealed that $50 \%$ had been fed breastmilk, $77 \%$ other types of milk, $63 \%$ porridge, $87 \%$ fruit, $78 \%$ soups, $64 \%$ the family meal, $58 \%$ meals including beans and $36 \%$ soup or meals containing meat.

In the age group 6 to 9 months, $48 \%$ of children were fed breastmilk and a savory meal (soup and/or the family meal). Of those children who were not in TCF, $14.1 \%$ were fed breastmilk but no savory meal, $77.1 \%$ were fed a savory meal, but not breastmilk and $8.8 \%$ were fed neither.

It will be observed in Figure 1 that the probability of a 6 -month-old child being fed soup is elevated (78\%), while the chance of eating the family meal is low (39\%). It will also be noted that, at $59 \%$, the probability of a child being fed breastmilk is lower than for other milks (70\%) and for porridge $(63 \%)$. If we consider other types of milk and porridge together, (milk-based meals), the probability rises to $82 \%$.

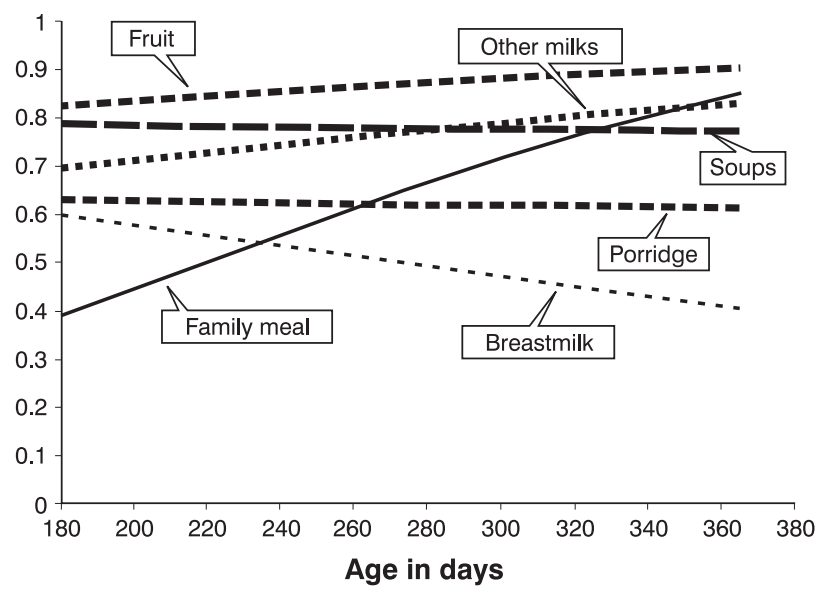

Figure 1 - Probabilities for the consumption of foods/preparations by children aged 6 to 12 months of age (AMAMUNIC-SP, 2004)

Analyzing the tendency of breastmilk consumption, it is observed that there is a significant reduction during the second 6 months of life, where the probability at 6 months is $59 \%$ but by 12 months it is $40 \%$. In contrast, the consumption of other types of milk varies between 70 and $83 \%$ at these ages.

The level of porridge consumption remained practically unaltered throughout the age range, at around $60 \%$. The 
proportion of children being fed the family meal was only greater than the proportion being given soup from 11 months of age on.

The level of fruit consumption, irrespective of presentation, was high ( 83 to $91 \%$ ) and did not vary by age.

When we analyzed the consumption of foods that provide iron, whether as soups or in the family meal, we observed that the probability of a 6-month-old child consuming these foods was $66 \%$. Independently, the probabilities for consumption of soup with meat, meals including beans and meals containing meat were 54, 34 and $25 \%$, respectively. The tendency to feed this type of food improves close to 12 months (Figure 2).

Table 1 lists the results of the bivariate analysis and multiple logistic regression analysis of associations between maternal characteristics consumption of milky meals, soups and family meals. The results indicate that consumption of milky meals is associated with primiparous mothers, mothers employed outside the home and mothers who studied for more than 8 years, similar to the consumption of soups, where mothers aged more than 20 years were also associated with consumption. The family meal was associated with mothers aged less than 20 years, mothers who did not work away from the home, mothers with less years' education and mothers with previous children. It will also be noted that these results remain unaltered when adjusted for the other variables that make up the model.

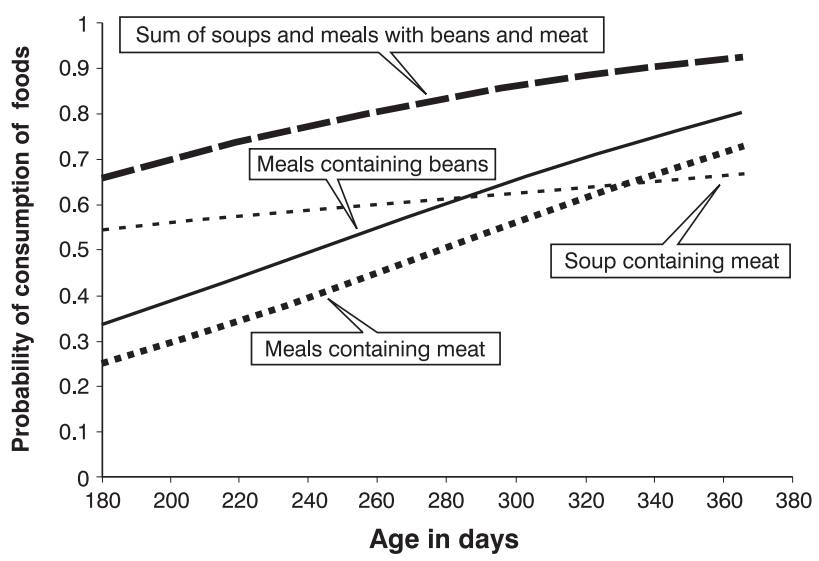

Figure 2 - Probabilities of children aged 6-12 months being fed meals containing beans and/or meat (AMAMUNIC-SP, 2004)

\section{Discussion}

While the information collected here on the foods/preparations consumed during 24 hours cannot provide quantities or frequency consumption, nor allow the nutritional value of these children's diets to be analyzed. It does make it possible to establish the tendencies of this age group's consumption, and gives an idea of the feeding patterns of infants, considering the significant number of children studied in the state.

Just $59 \%$ of the children in the study population were being breastfed at 6 months, and by 12 moths this proportion had reduced to $40 \%$. These data are similar to those found by a study of breastfeeding prevalence in Brazilian state capitals, which observed that, $69 \%$ of

Table 1 - Estimated odds ratios for associations between consumption of foods/preparations by children aged 6 to 12 months and maternal variables (AMAMUNIC-SP, 2004)

\begin{tabular}{|c|c|c|c|c|c|c|c|}
\hline \multirow[b]{2}{*}{ Maternal variables } & \multirow[b]{2}{*}{$\%$} & \multicolumn{2}{|c|}{ Milky meals } & \multicolumn{2}{|c|}{ Soups } & \multicolumn{2}{|c|}{ Family meals } \\
\hline & & COR & aOR & COR & aOR & COR & aOR \\
\hline \multicolumn{8}{|l|}{ Age (years) } \\
\hline$\geq 20$ & 85.9 & 1 & 1 & 1 & 1 & 1 & 1 \\
\hline$<20$ & 14.1 & 1.06 & 1.08 & 0.63 & 0.64 & 1.18 & 1.18 \\
\hline $95 \% \mathrm{CI}$ & & $(0.99-1.13)$ & $(0.99-1.16)$ & $(0.60-0.66)$ & $(0.60-0.68)$ & $(1.12-1.24)$ & $(1.11-1.25)$ \\
\hline \multicolumn{8}{|l|}{ Primiparous } \\
\hline No & 54.4 & 1 & 1 & 1 & 1 & 1 & 1 \\
\hline Yes & 45.6 & 1.31 & 1.17 & 1.23 & 1.08 & 0.87 & 0.88 \\
\hline Employment outside home & & $(1.25-1.37)$ & $(1.10-1.24)$ & $(1.18-1.28)$ & $(1.03-1.14)$ & $(0.84-0.90)$ & $(0.85-0.92)$ \\
\hline Yes & 33 & 1 & 1 & 1 & 1 & 1 & 1 \\
\hline No & 67 & 0.60 & 0.62 & 0.71 & 0.83 & 1.21 & 1.14 \\
\hline $95 \% \mathrm{CI}$ & & $(0.56-0.62)$ & $(0.59-0.66)$ & $(0.80-0.74)$ & $(0.78-0.87)$ & $(1.16-1.25)$ & $(1.09-1.19)$ \\
\hline \multicolumn{8}{|l|}{ Education } \\
\hline$>8$ years & 51.8 & 1 & 1 & 1 & 1 & 1 & 1 \\
\hline$\leq 8$ years & 48.2 & 0.78 & 0.85 & 0.56 & 0.62 & 1.34 & 1.29 \\
\hline $95 \% \mathrm{CI}$ & & $(0.74-0.81)$ & $(0.80-0.89)$ & $(0.53-0.58)$ & $(0.59-0.65)$ & $(1.29-1.38)$ & $(1.24-1.34)$ \\
\hline
\end{tabular}

$95 \% \mathrm{Cl}=95 \%$ confidence interval; $\mathrm{cOR}=$ crude odds ratio; $\mathrm{aOR}=$ adjusted odds ratio. 
children were being breastfed at around 6 months and 41\% at around 12 months of age. ${ }^{11}$ It should be pointed out that the recommendation is for children to receive both breastmilk and other foods until 2 years of age or more, in order to guarantee good health. While the protection offered by breastmilk is most evident during the first 6 months of life, the advantages can extend long beyond this period. ${ }^{3,5}$ Breastmilk can contribute up to $2 / 3$ of energy intake and continues to be an important source of fats, vitamin A, calcium and riboflavin up to the second year of life. ${ }^{12}$

In order to be classified as on TCF, children aged 6 to 9 months should be being fed, breastmilk and savory meals to meet their energy and nutrient requirements. Analysis revealed that less than half the children were meeting this recommendation (48\%). This result is similar to data for Brazil (48.9\%) and the Southeast region of Brazil (45.4\%) for $1999 .{ }^{11}$

At 6 months of age, the probability of a child being fed meals based purely on milks and porridges is $82 \%$, indicating a possibility that an adequate supply of nutrients may not be available during a phase characterized by accelerated infant growth and development. These findings have also been reported by other studies, in which cow's milk and thickeners play a major role in infant feeding. ${ }^{13-16}$ In Brazil, the Multicenter Dietary Intake Study (1999) also observed an elevated proportion of milk and its derivatives, thickeners and cereals in the diets of children aged 6 to 24 months. ${ }^{17}$

Excessively milky diets have been identified as one of the causes of anemia during the first years of life. Liquid cow's milk is itself a poor source of iron and can also inhibit absorption of the iron present in some other foods if given concomitantly, in addition to provoking micro-hemorrhages in the intestinal mucosa of children less than 1 year old. ${ }^{18-20}$

The results presented here demonstrate that the probability of a 6 -month-old child being fed soup is $78 \%$, whereas the chance of being given the family meal is $39 \%$. The density to which these soups are prepared should be a concern to health professionals, since the ideal is that they be pasty, closer to a purée, in order that they achieve the minimum desirable energy density. ${ }^{21}$ It is known that mothers feed more liquid than solid meals to their children because of lack of time when feeding or worries about choking and/or constipation. ${ }^{22}$ These concerns can be set aside since at this age children already have firm enough gums and neurological maturity sufficient to chew and swallow. ${ }^{5}$

After 6 months of age children should be gradually introduced to other foods, it being necessary to guarantee energy supply with foods with high energy densities and that are rich in micronutrients. The gastric capacity of children at this age is approximately $200 \mathrm{~mL}$; this being so preparations such as milk, porridges and soups that are overly dilute frequently do not achieve the desired energy concentration and should neither be used nor recommended. $5,21,22$

In this study, the analysis of data on the probability of consumption of iron-rich foods in preparations such as soups containing meat, meals including beans and meals with meat demonstrated that the child of a child receiving a meal containing iron-rich foods is $66 \%$ at 6 months of age, reaching $90 \%$ at 12 months.

Many studies, in addition to demonstrating an elevated prevalence of iron deficiency anemia among children under 5 years old, attribute the fact, in part, to low breastmilk intake and, in part, to an insufficient supply of the nutrient in the diet. ${ }^{17,23-26}$ Late introduction of meat and beans into the diet of children was also observed in other studies. ${ }^{14,27,28}$ On a national level, the 1996 National Demographic and Health Census (Pesquisa National sobre Demografia and Saúde - PNDS) also demonstrated low intake of meat during the first year of life. ${ }^{29}$

Overall fruit consumption during the period was very high $(87 \%)$, and the probability of children being given fruit at 6 months of age, irrespective of the presentation, is also elevated $(82 \%)$. These finding corroborate other studies that have identified fruit as the next most eaten food after milk. These foods are those offered by preference at the start of complementary feeding, because they are suggested by health professionals, because children accept them easily and because there is a plentiful supply. ${ }^{14,15,27}$

The results on complementary feeding from the WHO multicenter study, undertaken in six countries with children up to 2 years old, demonstrate that the mean age of introduction of complementary foods was 5.4 months. Furthermore consumption of soup was more common in Brazil, Oman and Ghana and less frequent in India, Norway and the USA; consumption of grains was elevated for the majority of children, with the exception of the Brazilians at 6 months of age (just $24 \%$ ). ${ }^{30}$

Analyzing the profile of the mothers who offered more soups than meals to their children, we observed that they had studied for longer, worked outside the home, were primiparous and were over 20 years old. This profile indicates mothers with better discernment and possibly access to information on management and care of infants, who have perhaps been advised to do this by health professionals in general or family members. The introduction of soups to the diets of infants is not incorrect; 
however we cannot state that it guarantees, depending on preparation, the necessary nutritional support, as discussed earlier, and could even contribute to nutritional deficiencies in children in this age group.

The results of this study indicate a need for intervention and guidance on infant nutrition on the part of health professionals, considering that the majority of children are starting complementary feeding in an unsuitable manner, which can have negative repercussions for their health.

\section{References}

1. Pipes LP. Nutrition in infancy. In: Mahan LK, Escot-Stump S. Krause's food, nutrition \& diet therapy. 9th ed. Philadelphia: WB Saunders; 1996. p. 213-30.

2. World Health Organization/The United Nations Children's Fund. Complementary feeding of young children in developing countries: a review of current scientific knowledge. Geneva: WHO/NUT/98; 1998.

3. World Health Organization. The optimal duration of exclusive breastfeeding: a systematic review. WHO/01.08. WHO/FCH/CAH/01.23. Geneva: WHO; 2001.

4. Monte CM, Giugliani ER. Recomendações para a alimentação complementar da criança em aleitamento materno. J Pediatr (Rio J). 2004;80(5 Supl):S131-41.

5. Brasil, Ministério da Saúde/Organização Pan-Americana da Saúde. Guia alimentar para crianças menores de 2 anos de idade. Serie A. Normas e manuais técnicos. Brasília, DF: Ministério da Saúde; 2005.

6. Ramos M, Stein LM. Desenvolvimento do comportamento alimentar infantil. J Pediatr (Rio J). 2000;76 Supl 3:S229-37.

7. Silva NN. Amostragem probabilística. São Paulo: Edusp; 1998.

8. Kitoko PM, Rea MF, Venancio SI, de Vasconcelos AC, dos Santos EK, Monteiro CA. Situação do aleitamento materno em duas capitais brasileiras: uma análise comparada. Cad Saude Publica. 2000;16:1111-19.

9. Finney DJ. Probit analysis. 3rd ed. Cambridge: Cambridge University Press; 1980.

10. Hosmer DW, Lemeshow S. Applied logistic regression. New York: John Wiley \& Sons; 1989.

11. Brasil, Ministério da Saúde, Secretaria de Políticas de Saúde, Área de Saúde da Criança. Pesquisa de prevalência de aleitamento materno nas capitais brasileiras e no Distrito Federal. Brasília: PPAM-CDF; 1999.

12. Prentice A, Paul AA. Contribution of breast-milk to nutrition during prolonged breast-feeding. In: Atkinson SA, Hanson L, Chandra R, editors. Human lactation 4: breast-feeding nutrition, infection and infant growth in developed and emerging countries. Saint John's: ARTS Biomedical; 1990. p 87-102.

13. Tudisco ES, Marin P, Shrimpton R, Costa M, Donohue R. Alimentação no desmame em áreas periurbanas de quatro capitais brasileiras: resultados preliminares. J Pediatr (Rio J). 1988;64:231-6.

14. Souza SB, Szarfac SC, Souza JMP. Prática alimentar no primeiro ano de vida em crianças atendidas em centros de saúde escola no município de São Paulo. Rev Nutr. 1999;12:167-74.
15. Oliveira LPM, Assis AMO, Pinheiro SMC, Prado MS, Barreto ML. Alimentação complementar nos primeiros dois anos de vida. Rev Nutr. 2005;18:459-69.

16. Faria Junior G, Osorio MM. Padrão alimentar de crianças menores de cinco anos. Rev Nutr. 2005;18:793-802.

17. Brasil, Ministério da Saúde. Padrões de alimentação nos primeiros dois anos de vida: estudo multicêntrico em cinco capitais brasileiras. Brasília: Ministério da Saúde; 1999.

18. Olivares $M$, Walter T, Hertrampf E, Pizarro F. Anaemia and iron deficiency disease in children. Br Med Bull. 1999;55:534-43.

19. Levy-Costa RB, Monteiro CA. Consumo de leite de vaca e anemia na infância no Município de São Paulo. Rev Saude Publica. 2004;38:797-803.

20. Oliveira MA, Osorio MM. Consumo de leite de vaca e anemia ferropriva na infância. J Pediatr (Rio J). 2005;81:361-7.

21. World Health Organization. Complementary feeding: report of the global consultation and summary of guiding principles for complementary feeding of the breastfed child. Geneva: WHO; 2002.

22. Organização Mundial da Saúde. Aconselhamento em alimentação infantil: curso integrado - guia do treinador. Geneva: WHO; 2005.

23. Mondini L, Philippi ST, Gambardella AMD. Mudanças na composição e adequação nutricional das dietas. In: Monteiro CA, organizador. Como e por que melhoram (ou pioram) os indicadores de saúde e nutrição na infância? O caso da cidade de São Paulo na segunda metade do século XX. São Paulo: NUPENS/USP; 1999

24. Monteiro CA, Szarfarc SC, Mondini L. Tendência secular da anemia (1984-1996). Rev Saude Publica. 2000;34(6 Supl):62-72.

25. Osório MM, Lira PI, Batista-Filho M, Ashworth A. Prevalence of anemia in children 6-59 months old in the state of Pernambuco, Brazil. Rev Panan Salud Publica. 2001;10:101-7.

26. Silva LSM, Giugliani ERJ, Rangel D, Aerts GC. Prevalência e determinantes da anemia em crianças de Porto Alegre, RS, Brasil. Rev Saude Publica. 2001;35:66-73.

27. Marchioni DM, Latorre Mdo R, Szarfac SC, de Souza SB. Complementary feeding: study on prevalence of food intake in two health centers of São Paulo city. Arch Latinoam Nutr. 2001; $51: 161-6$.

28. Simon VGN, Souza JMP, Souza SB. Introdução de alimentos complementares e sua relação com variáveis demográficas e socioeconômicas, em crianças no primeiro ano de vida, nascidas em Hospital Universitário no município de São Paulo. Rev Bras Epidemiol. 2003;6:29-38.

29. Sociedade Civil Bem Estar Familiar no Brasil (BEMFAM). Pesquisa nacional sobre demografia e saúde 1996: amamentação e situação nutricional das mães e crianças. Rio de Janeiro: BEMFAM; 1997.

30. World Health Organization/Multicentre Growth Reference Study Group. Complementary feeding in the WHO Growth Reference Study. Acta Paediatr. 2006;95(450 Suppl):27-37.

Correspondence:

Silvia Regina DM Saldiva

Rua Santo Antonio, 590, Bela Vista

CEP 01314-000 - São Paulo, SP - Brazil

Tel.: +55 (11) 3293.2289, +55 (11) 3293.2267

E-mail: smsaldiva@isaude.sp.gov.br 